\title{
Understanding pRb: toward the necessary development of targeted treatments for retinoblastoma
}

\author{
Uma M. Sachdeva and Joan M. O’Brien \\ Scheie Eye Institute, University of Pennsylvania School of Medicine, Philadelphia, Pennsylvania, USA.
}

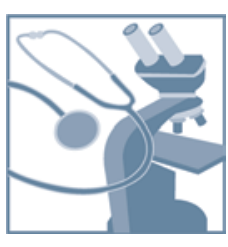

Retinoblastoma is a pediatric retinal tumor initiated by biallelic inactivation of the retinoblastoma gene (RB1). $R B 1$ was the first identified tumor suppressor gene and has defined roles in the regulation of cell cycle progression, DNA replication, and terminal differentiation. However, despite the abundance of work demonstrating the molecular function and identifying binding partners of $\mathrm{pRb}$, the challenge facing molecular biologists and clinical oncologists is how to integrate this vast body of molecular knowledge into the development of targeted therapies for treatment of retinoblastoma. We propose that a more thorough genetic understanding of retinoblastoma would inform targeted treatment decisions and could improve outcomes and quality of life in children affected by this disease.

Retinoblastoma (RB) is the most common primary intraocular malignancy of childhood, affecting roughly 1 in 15,000 children. When diagnosed at an early stage and treated with standard protocols of systemic chemotherapy and focal consolidative therapy, near-complete cure rates are possible, with most patients retaining normal vision in at least one eye (1). If left untreated, however, RB can lead to devastating consequences, including blindness and death, with tumors disseminating throughout the retina, optic nerve, brain parenchyma, and systemically. While early diagnosis and aggressive treatment strategies have made these outcomes rare in developed countries (2), RB remains a potentially devastating disease in developing nations, where intensive chemotherapy and long-term followup are not as readily available $(2,3)$. Standard chemotherapy protocols include two- or three-drug regimens using alkylating and DNA-damaging agents along with cytoskeletal inhibitors, which can be associated with significant toxicities. Systemic carboplatin treatment has been associated with nephrotoxicity and ototoxicity $(4,5)$, while local treatment has been associated with multiple ocular complications, including reduced motility (6), severe pseudo-preseptal cellulitis (7), and optic atrophy with ischemic necrosis $(8,9)$, resulting in vision loss. Etoposide treatment has been associated with secondary leukemias $(10,11)$. Patients with advanced disease require, in addition to chemotherapy, external beam radiation (EBR) and/or enucleation, with the potential result of disfigurement and secondary malignancies (12). EBR is known to cause mid-facial hypoplasia in young patients and increase the risk for development of soft tissue sarcomas, brain tumors, and osteosarcomas, among other cancers $(13,14)$. Therefore, while treatment of RB is remarkably effective, it is complicated by the extensive side effects of non-targeted chemotherapy agents, radiation, and surgical enucleation (Table 1). Despite extensive knowledge regarding the genetics underlying the development of RB, there has been limited progress in developing targeted treatments for this disease.

Conflict of interest: The authors have declared that no conflict of interest exists. Citation for this article: J Clin Invest. 2012;122(2):425-434. doi:10.1172/JCI57114.

\section{$R B 1$ mutations in retinoblastoma}

$\mathrm{RB}$ results from biallelic inactivation or loss of the retinoblastoma 1 gene (RB1), located on the long arm of chromosome 13 (13q14.2). Roughly $40 \%$ of RB cases are heritable, with $R B 1$ mutations occurring in the germline and present in all somatic cells, while $60 \%$ of RB cases are non-heritable, with mutations arising locally within the developing retina (15). Despite requiring loss of both $R B 1$ alleles, the genetics of heritable RB demonstrate autosomal dominance, as almost all children who possess one mutated germline copy of $R B 1$ develop the disease. In heritable cases, the initial mutated $R B 1$ allele may be known to be present within the family (familial RB, 25\% of heritable cases) or it may have occurred de novo in the parental gametes (sporadic heritable RB, 75\% of heritable cases) (15). In both cases, mutation of the second allele occurs within the developing retina, resulting in the development of intraocular tumors. In sporadic, non-heritable $\mathrm{RB}$, which comprises the majority of $\mathrm{RB}$ cases, both $R B 1$ mutations occur locally within the affected retina. For this reason, most sporadic non-heritable cases are unilateral, while all bilateral cases have been found to result from heritable germline mutations (15). It remains unknown why the retina is so susceptible to mutation at the RB1 locus, and an enhanced understanding of why loss of heterozygosity frequently occurs at this locus would improve efforts to both treat and prevent this devastating disease.

The disease burden of patients affected with RB correlates with the mode of inheritance of their mutation. In familial RB, carriers of a null $R B 1$ allele develop bilateral, multifocal tumors with very high penetrance ( $90 \%-100 \%)$, while carriers of uncommon partial function mutations more frequently develop "low-penetrance retinoblastoma," a less severe form of the disease characterized by unilateral involvement, benign retinoma, and decreased penetrance (16). Roughly $10 \%$ of children with heritable forms of RB also develop primary midline intracranial neoplasms, most commonly primitive neuroectodermal tumors, a condition referred to as "trilateral retinoblastoma" (17). Patients with heritable $R B 1$ mutations also have an elevated lifetime risk for developing second primary malignancies, including osteogenic and soft tissue sarcomas, melanomas, and lung and bladder cancers $(14,17-19)$. These tumors collectively constitute the RB1 cancer syndrome. Further- 


\section{Table 1}

International classification system for retinoblastoma

$\begin{array}{ll}\text { Group } & \text { Clinical characteristics } \\ \text { A: Small } & \leq 3 \mathrm{~mm} \text { height; } \geq 2 \text { disc diameters } \\ & \text { from fovea; } \geq 1 \text { disc diameter from } \\ & \text { optic nerve }\end{array}$

B: Medium $\quad>3 \mathrm{~mm}$ height; clear subretinal fluid $<3 \mathrm{~mm}$ from tumor margin

\section{C: Confined, Localized vitreous seeding or medium subretinal seeding or both}

\begin{abstract}
E: Enucleation, No visual potential or tumor in anterior advanced segment/ciliary body or neovascular glaucoma or vitreous hemorrhage or phthisical eye or orbital cellulitis-like appearance or involvement of optic nerve or extraocular disease present
\end{abstract}

Treatment (toxicities)

Argon-YAG laser (vitreous seeding

if power too high) ${ }^{A}$

Diode laser-induced hyperthermia

(tissue damage, vitreous seeding) ${ }^{A}$

Cryotherapy (retinal tears, chorioretinal atrophy) ${ }^{\mathrm{A}}$

Brachytherapy (radiation retinotherapy) ${ }^{A}$

Vincristine + low-dose carboplatin, up to 6 cycles (neurotoxicity, hyponatremia, nephrotoxicity, ototoxicity)

Focal therapy for 2-6 cycles (vitreous seeding, radiation retinotherapy, retinal tears)

Vincristine + high-dose carboplatin + etoposide + G-CSF, up to 6 cycles (neurotoxicity, hyponatremia, nephrotoxicity, ototoxicity, secondary leukemias)

Focal therapy (vitreous seeding, radiation retinopathy, retinal tears)

Possible subtenon carboplatin (decreased ocular motility, psuedo-preseptal cellulitis, optic atrophy with ischemic necrosis)

Vincristine + high-dose carboplatin + etoposide + G-CSF, up to 6 cycles (neurotoxicity, hyponatremia, nephrotoxicity, ototoxicity, secondary leukemias)

EBR (mid-facial hypoplasia, soft tissue and osteosarcoma, brain tumors)

Possible subtenon carboplatin (decreased ocular motility, psuedo-preseptal cellulitus, optic atrophy with ischemic necrosis)

Enucleation; prophylactic 3-agent chemotherapy if high-risk features for disease dissemination observed on consensus pathologic evaluation (neurotoxicity, hypnatremia, nephrotoxicity, ototoxicity, secondary leukemias)

\section{Prognosis}

Good visual and overall prognosis; usually eradicated

Good visual prognosis

Visual prognosis variable

Variable visual prognosis; high morbidity from treatment
High morbidity
from treatment;
no visual potential

AFocal therapies. Clinical characteristics associated with classification groups, current treatment strategies, and toxicities of current systemic chemotherapeutic approaches are shown.

more, the predisposition toward secondary tumor development is significantly increased by the radiation therapy used to treat more advanced primary presentations of RB (14).

Since its discovery, $\mathrm{pRb}$, the protein product of $R B 1$, has become one of the most studied proteins of all time. pRb plays critical roles in regulating multiple pathways that affect oncogenesis (Figure 1), including cell proliferation, death, and differentiation, through regulation of the cell cycle, apoptosis, senescence, and genome maintenance (20). pRb affects these pathways primarily through direct and indirect suppression of gene and protein expression.

Despite the tremendous progress in determining the cellular function and genetic inheritance patterns of mutations in $R B 1$, major questions regarding our understanding of $\mathrm{RB}$ as a disease remain, including the function of specific $R B 1$ mutations and the potential for tailoring treatments to specific gene and protein defects. Furthermore, despite extensive research, the RB cell of origin remains a subject of continued debate, slowing the development of targeted approaches. This review highlights advances in our understanding of the molecular function of $\mathrm{pRb}$, including its role in the development and progression of RB, as well as the major areas in RB research that remain to be explored, toward the necessary development of more targeted approaches for RB treatment. These targeted approaches should be more effective and less toxic when the myriad functions of $\mathrm{pRb}$ are fully elucidated and considered.

\section{pRb function in cell cycle arrest}

$\mathrm{pRb}$ is a transcriptional cofactor and adaptor protein that functions primarily as a regulator of gene expression, influencing 


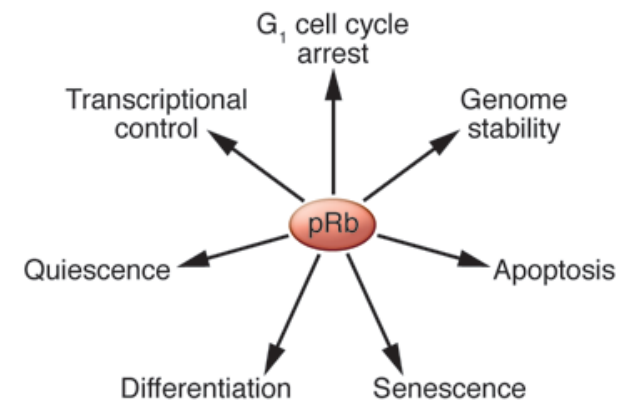

Figure 1

Cellular functions of $\mathrm{pRb}$. $\mathrm{pRb}$ is required for regulation of multiple critical cellular processes, including proliferation, differentiation, maintenance of genome integrity, quiescence, and senescence $(47,123)$.

multiple cell processes required for embryonic growth and development. These processes include cell proliferation, senescence, apoptosis, differentiation, and chromatin remodeling (20). pRb is required for terminal differentiation of myocytes through transcriptional synergy with MyoD, and promotes its functional interaction with the coactivator myocyte enhancer factor 2 (MEF2) (21). pRb also binds directly to histone deactylase 1 (HDAC1) and prevents it from associating with $\mathrm{MyoD}$, indirectly promoting the expression of MyoD transcriptional targets by preventing their deacetylation (21). pRb also plays important roles in the fate determination, differentiation, survival, and migration of developing neurons $(22,23)$.

$\mathrm{pRb}$ and its related proteins p107 and p130 comprise the family of "pocket" proteins, categorized according to their structural and functional similarities, including the presence of a large pocket domain, which serves as the binding site for many of their interacting proteins. The large pocket of $\mathrm{pRb}$ is the site of the majority of naturally occurring mutations in $R B 1$ and contains distinct sequences required for the binding of two critical mediators of pRb-induced cell cycle arrest, E2F and Skp2 (24-26). While pRb is the predominant pocket protein expressed in murine proliferating postnatal retinal progenitor cells, p107 is upregulated in response to loss of $\mathrm{pRb}$ in mice and can at least partially compen- sate for absence of this protein (27). This compensation has not been observed in humans, which may partially explain why RB is a uniquely human disease.

E2F transcription factors regulate the expression of multiple genes involved in the progression through $\mathrm{G}_{1}$ and $S$ phases of the cell cycle, in DNA metabolism, and in cell proliferation. pRb binds to DNA-bound E2Fs and inhibits their effects on gene expression by preventing the binding of transcriptional co-activators, and through recruitment of HDACs, ATPases, and DNA methyltransferases to the promoters of target genes (ref. 28 and Figure 2). pRb specifically binds E2F1, -2 , and -3 family members $(28,29)$. E2F1-E2F3 are transcriptional activators and have been found to play an oncogenic role in multiple human cancers, with increased expression levels observed in hepatocellular carcinoma, bladder cancer, glioblastoma, liposarcoma, and breast and ovarian tumors, in addition to $\mathrm{RB}(30)$. During the initial stages of $\mathrm{G}_{1}$, as well as in quiescent or growth-inhibited cells, pocket proteins bind E2F family members to inhibit their transcriptional effects, which would otherwise promote cell cycle progression. The cell cycle regulators under the control of E2F transcription factors include cyclins $\mathrm{A}$ and E, Cdc2, Cdc25C, and p21 (ref. 28 and Figure 2).

The F-box protein Skp2 also plays an important role in cell cycle progression, regulating the transition to $\mathrm{S}$ phase, as well as cellular senescence, through interaction with the cell cycle inhibitory protein $\mathrm{p} 27$. When activated, p27 blocks cell cycle progression through the $\mathrm{G}_{1}$-S transition by inhibiting the checkpoint cyclindependent kinase cyclin E-CDK2 (31-33). The cyclin E-CDK2 complex functions to inhibit $\mathrm{pRb}$ activity by phosphorylating $\mathrm{pRb}$ and preventing its association with E2F transcriptional activators (ref. 34 and Figure $3 \mathrm{~A}$ ). In the presence of growth-promoting signals, $\mathrm{Skp} 2$ binds $\mathrm{p} 27$, resulting in $\mathrm{p} 27$ degradation. In the absence of proliferative signals, $\mathrm{pRb}$ binds $\mathrm{Skp} 2$, resulting in Skp2 degradation, subsequent p27 accumulation, and $\mathrm{G}_{1}$ arrest (Figure 3B). The mechanism underlying pRb/Skp2/p27-mediated $\mathrm{G}_{1}$ arrest is independent of the pRb-E2F interaction (26), indicating that $\mathrm{pRb}$ exerts its antiproliferative, tumor-suppressive, and both pro- $(35)$ and antiapoptotic $(36,37)$ activities through multiple parallel, though intersecting, pathways. A functional separation between the $\mathrm{pRb} / \mathrm{Skp} 2 / \mathrm{p} 27$ and $\mathrm{pRb} / \mathrm{E} 2 \mathrm{~F}$ pathways in vivo is demonstrated by the presence of $R B 1$ mutations that inhibit one of these pathways, but leave the other pathway intact.

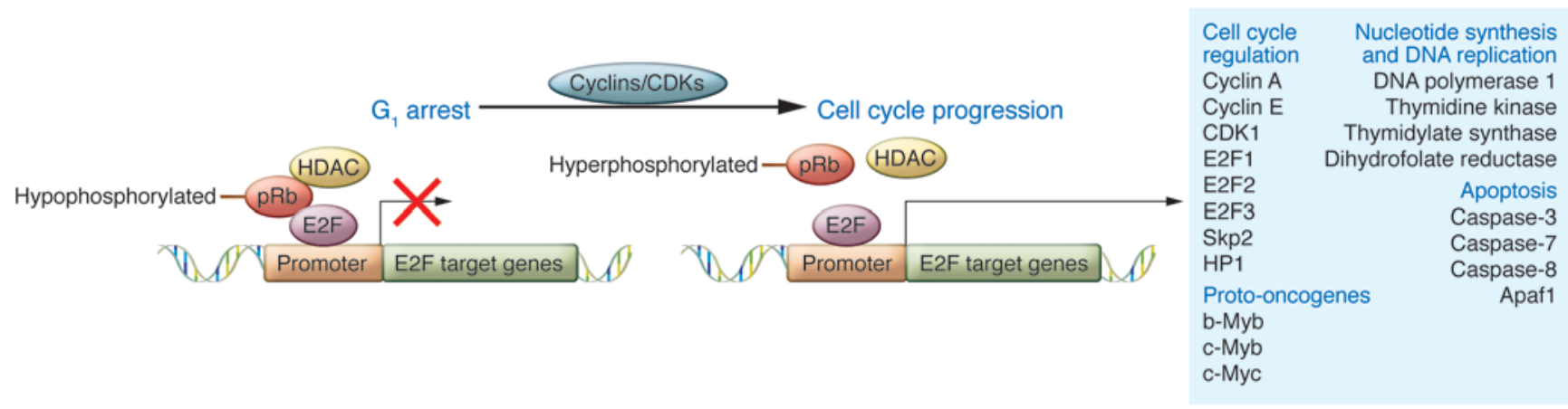

Figure 2

Regulation of E2F-dependent gene expression by $\mathrm{pRb}$. pRb binds to DNA-bound E2F transcriptional regulators and suppresses their target gene expression through recruitment of HDACs, co-repressors, and chromatin remodeling enzymes. It also serves to inhibit the binding of co-activating transcription factors to E2F-bound promoters. Genes regulated by $p R b-E 2 F$ include regulators of cell cycle progression at the $\mathrm{G}_{1} / \mathrm{S}$ transition, enzymes required for DNA synthesis, proto-oncogenes, apoptosis regulators, and modifiers of pRb/E2F pathway activity $(47,57,124,125)$. 


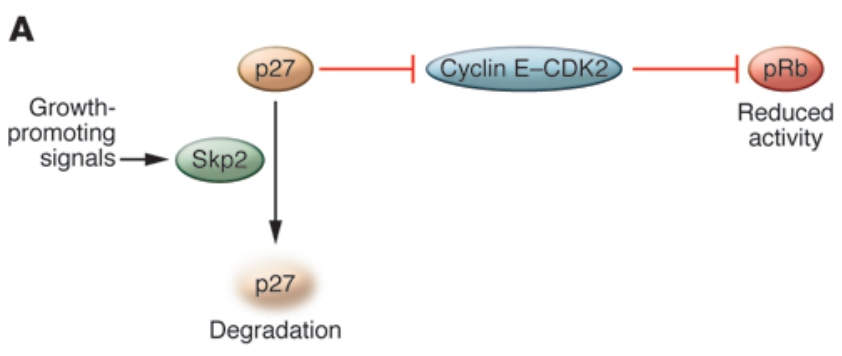

B

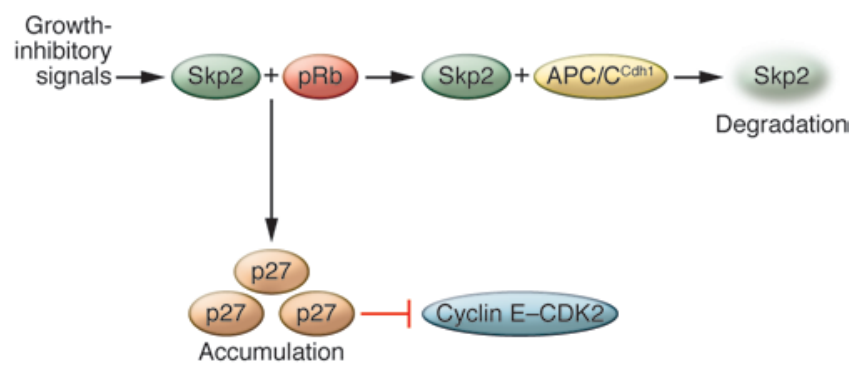

\section{Figure 3}

The Skp2/p27/pRb pathway in the regulation of cell cycle progression. (A) In response to proliferative signals, cellular levels of Skp2 increase, resulting in Skp2 binding to p27 and targeting it for degradation. This degradation of p27 relieves p27-mediated inhibition of the cyclin ECDK2 complex during late $G_{1}$, allowing for phosphorylation and inactivation of $p R b$ and promoting $G_{1}$ progression to $S$ phase. (B) In the absence of proliferative signals, $\mathrm{pRb}$ is hypophosphorylated and binds to Skp2, preventing it from binding to p27. Skp2 is then complexed with APC/CCah1 and is targeted for proteasomal degradation. Free p27 is then able to bind cyclin E-CDK2 and inhibit its activity, resulting in continued $p R b$ activity and $\mathrm{G}_{1}$ cell cycle arrest.
The RbR661W mutation is a naturally occurring partially penetrant mutation of $R B 1$ that blocks the $\mathrm{pRb} / \mathrm{E} 2 \mathrm{~F}$ pathway, but maintains the $\mathrm{pRb} / \mathrm{Skp} 2 / \mathrm{p} 27$ pathway (26). Patients harboring the R661W mutation either have unilateral disease or are unaffected carriers (38), which suggests that molecular genetic analysis of all patients with heritable $R B 1$ mutations may inform treatment decisions, based on the severity of disease and penetrance associated with specific $R B 1$ mutations.

In addition to E2F and Skp2 binding sites, the A/B pocket of $\mathrm{pRb}$ contains a separate binding domain, the LXCXE binding cleft (Figure 4), by which the $\mathrm{pRb}$ protein binds to partners that also share an LXCXE binding motif. These include several chromatin remodeling factors that participate in transcriptional repression of E2F target genes, including HDAC1, as well as Cdh1, the partner of APC $(20,39-41)$. The LXCXE binding cleft is highly evolutionarily conserved and is the target of multiple viral oncoproteins that inactivate $\mathrm{pRb}$ to induce tumorigenesis $(42,43)$. The discovery of these viral oncoproteins led to the development of the first mouse models of RB, in which expression of viral transgenes was targeted to the developing retina. Among these viral oncoproteins are the simian virus 40 (SV40) large $\mathrm{T}$ antigen, adenovirus E1A protein, and human papilloma virus E6 and E7 proteins, all of which possess an independently evolved LXCXE sequence (43).

Despite its evolutionary conservation and its function as the binding site for multiple viral oncoproteins, the LXCXE motif of pRB does not appear to serve a critical tumor-suppressive function. Disease-causing mutations in this motif are exceedingly rare and have only been observed in one human cancer cell line $(44,45)$. Mice genetically engineered to lack this domain are viable and do not develop tumors (46). Interestingly, however, the LXCXE motif does seem to play an important role in regulating the cellular response to toxic exposures, including ionizing radiation and chemotherapeutic agents. This motif has been found to be required to suppress the development of hepatocellular carcinoma following genotoxic stress in mice and to modulate the sensitivity of cultured cells to cisplatin (47). Of note, loss of pRb has also been shown to increase mouse fibroblast sensitivity to etoposide and mitomycin C (48) and increase the sensitivity of human breast cancer cells to multiple chemotherapeutic agents, including 5-fluorouracil (5-FU), methotrexate, cisplatin, as well as ionizing radiation $(49,50)$.

Roughly $90 \%$ of $\mathrm{pRb}$ mutations resulting in hereditary $\mathrm{RB}$ are null alleles $(16,51)$, suggesting that multiple functional domains of $\mathrm{pRb}$ contribute to tumor suppression and that tumorigenesis may result from a diversity of mutations that function to globally inactivate $\mathrm{pRb}(52)$. Some partially inactivating $\mathrm{pRb}$ mutations do occur that confer a lower risk for RB and have provided clues to the discrete tumor-suppressive functions of $\mathrm{pRb}(16,53)$. Mutant forms of RB1, such as the aforementioned RbR661W, have been isolated from patients with low-penetrance RB; these mutant proteins have lost the ability to bind E2Fs, but retain their ability to induce differentiation $(54,55)$. This finding suggests that different regions of the protein are responsible for regulating the diverse cellular functions of $\mathrm{pRb}$ and that the nature of the $R B 1$ gene mutation may dictate disease severity. The elucidation of more precise relationships between specific genetic mutations in $R B 1$ and the severity of disease phenotypes would therefore pave the way for the development of more targeted patient-specific therapies for RB.

\section{Regulation of $\mathrm{pRb}$ activity}

The activity of $\mathrm{pRb}$ is regulated through control of its phosphorylation state, which is modulated throughout the proliferating cell cycle (56-60). During $G_{1}$ and in quiescent cells that have exited the cell cycle, pRb is hypophosphorylated and able to bind E2F and other targets to function as an inhibitor of cell proliferation. In response to proliferative growth signals, $\mathrm{pRb}$ is successively phosphorylated by cyclin-dependent kinases (Figures 4 and 5), resulting in its inability to complex effectively with E2Fs (61). pRb is thus released from the promoters of E2F target genes, allowing binding of transactivators and expression of target genes that promote cell cycle progression into $S$ phase (Figure 5). Among the E2F target genes transcribed following $\mathrm{pRb}$ phosphorylation is Skp2 (62), so that both the E2F- and Skp2-dependent pathways are activated to promote cell cycle progression. The $\mathrm{pRb}$ protein contains 16 potential CDK phosphorylation sites (ref. 63 and Figure 4), although not all of these have been found to be phosphorylated in vivo. 


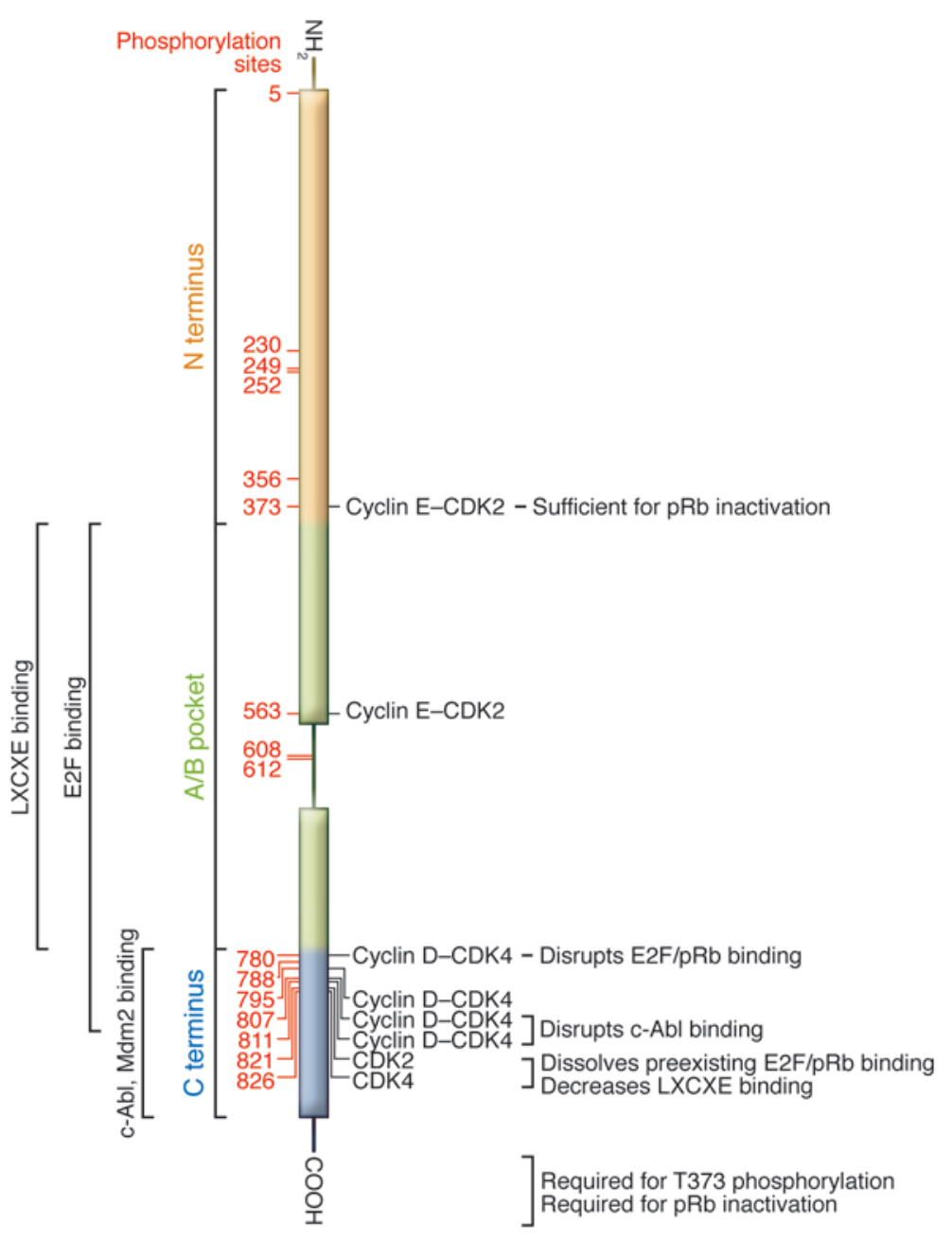

\section{Figure 4}

Functional domains of the $p R b$ protein. The A/B pocket, which contains the LXCXE motif, is required for binding of E2Fs, HDACs, and viral oncoproteins. The $\mathrm{N}$ terminus contains the phosphorylation site for the cyclin E-CDK2 complex, which is sufficient for $\mathrm{pRb}$ inactivation. The $\mathrm{C}$ terminus is required for $p R b$ inactivation and contains binding sites for the c-Abl proto-oncogene and the p53 inhibitor Mdm2. The pRb protein contains 16 CDK phosphorylation sites, which alter the binding characteristics and activity of $\mathrm{pRb}$ throughout the cell cycle. Mutations in the $R B 1$ gene are concentrated in the $\mathrm{A} / \mathrm{B}$ pocket.
Dephosphorylation and activation of $\mathrm{pRb}$ is controlled by phosphatases and cyclin-dependent kinase inhibitors (CDKIs) of the Ink4 (p15, p16, p18, and p19) and Cip/Kip (p21, p27, and p57) families (64). CDKIs respond to diverse antiproliferative signals, including DNA damage, senescence, and differentiation signals. Collectively, Ink 4 and Cip/Kip CDKIs positively regulate $\mathrm{pRb}$ by inhibiting its negative regulators, the activated cyclin-CDK complexes (Figure 5). Inactivation of cyclin-CDKs by CDKIs therefore results in cell cycle arrest in a pRb-dependent manner. Interestingly, despite this highly regulated cycle of phosphorylation, few mutations have been identified that affect $\mathrm{pRb}$ phosphorylation, as most highly penetrant mutations result in null alleles (52).

\section{Addition roles for $\mathrm{pRb}$ in cell cycle regulation}

$\mathrm{pRb}$ may also play a role in protecting against the development of chromosomal rearrangements through several distinct mechanisms. Inactivation of $\mathrm{pRb}$ results in deregulated expression of the E2F target gene MAD2, encoding a mitotic spindle checkpoint protein (65). This results in mitotic defects and aneuploidy in vitro (66), and Mad2 overexpression has been found to promote aneuploidy and tumorigenesis in transgenic mice (67). Interestingly, Mad2 is also overexpressed in many tumors, including RB (65), suggesting that this mechanism could contribute to the pathogenesis of the disease.
pRb also ensures chromosomal integrity by directing heterochromatin formation through interactions with two LXCXE-containing histone methyltransferases, Suv4-20h1 and Suv4-2 (68). Disruption of these interactions can result in slowed progression through mitosis and centromere fusion, chromosomal missegregation, and genomic instability (46). pRb regulates chromatin condensation, cohesion, and stability by promoting the centromeric localization of the CAP-D3/condensin II protein complex, an interaction that is evolutionarily conserved $(66,69)$. These findings suggest that additional mechanisms may underlie the development of $\mathrm{RB}$, including loss of the regulatory interactions between $\mathrm{pRb}$ and effectors of normal chromosomal segregation during mitosis. Aneuploidy of chromosomal arms $6 \mathrm{p}$ and $1 \mathrm{q}$ has been observed in heritable RB tumor samples (70) and has led to the identification of additional genes that might contribute to RB development and progression, as discussed below.

\section{Mouse models of retinoblastoma}

Despite the difficulty in generating accurate murine models of RB, much has been learned about the additional pathways required for the development of retinal tumors in animal models. The first heritable model of RB came from a transgenic system in which the SV40 T antigen was expressed under the control of a human leuteinizing hormone beta subunit promoter (LH $\beta-\mathrm{T}-\mathrm{Ag})$. 
A

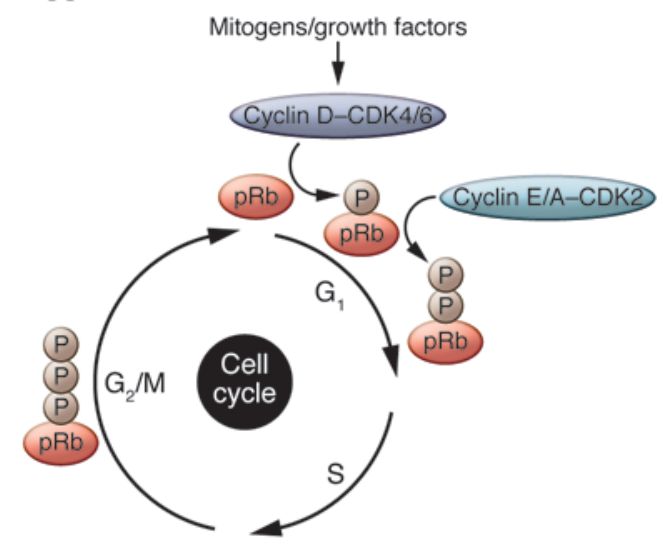

B

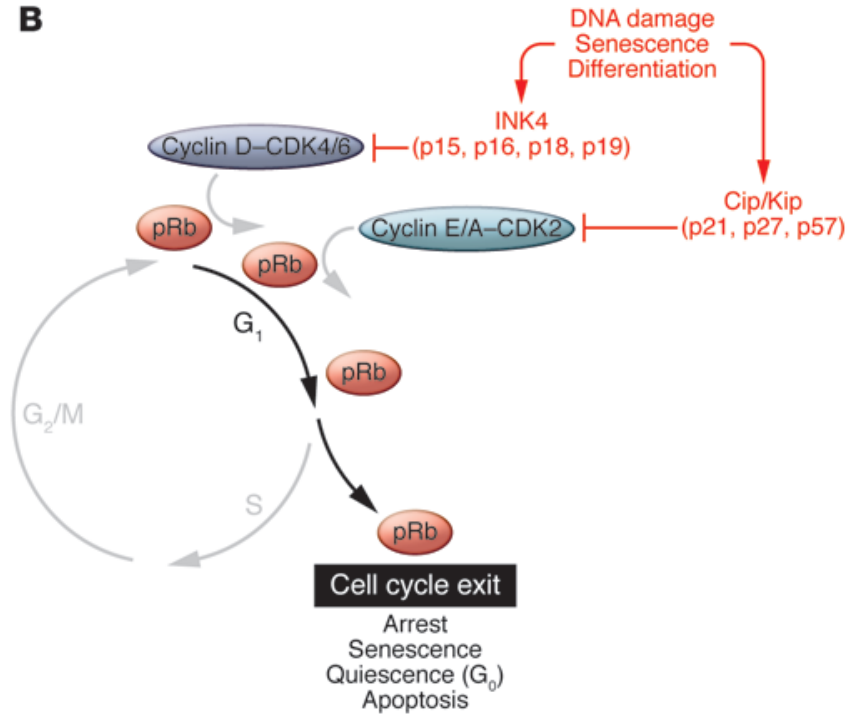

\section{Figure 5}

Regulation of $\mathrm{pRb}$ in coordination with the cell cycle. Quiescent cells contain hypophosphorylated, active pRb. (A) In response to mitogenic signaling, cylin D-CDK4 complexes phosphorylate $p R b$ and promote its subsequent phosphorylation by cyclin $E_{-}-C_{K} 2$ in late $G_{1}(28,126,127)$. These phosphorylation events result in inactivation of $\mathrm{pRb}$, allowing progression of the cell cycle past the $\mathrm{G}_{1} / \mathrm{S}$ transition and promoting $\mathrm{DNA}$ replication during $S$ phase. $p R b$ is further phosphorylated during $G_{2} / M$ phases of the cell cycle $(56,59,60)$. As mitosis comes to completion, $\mathrm{pRb}$ is de-phosphorylated and returns to its active, hypophosphorylated state. (B) In response to antiproliferative signals (red), CDKi, including Ink4 and Cip/Kip family members, are activated, resulting in inhibition of cyclin-CDK complexes and promoting pRb activity to cause $\mathrm{G}_{1}$ arrest and cell cycle exit.

Surprisingly, these mice develop retinal tumors at one to two months of age that are bilateral and multifocal, closely resembling heritable RB (71). The progression of disease displayed by these mice also closely reflected the natural history of human RB, with tumor spreading to invade the choroid, vitreous, optic nerve, and central nervous system. While strong expression of the LH $\beta$ promoter in the retina was unexpected, other transgenic models were developed using retina-specific promoters, including those of the interphotoreceptor retinoid-binding protein (IRBP), opsin, and alpha-A crystallin genes, which demonstrated varying degrees of disease severity and fidelity to human disease phenotypes (refs. 72-75 and reviewed in ref. 76).

From these models came the critical finding that the p53 tumor suppressor pathway plays an important role in the development of murine RB and may play a significant role in human disease pathogenesis. Expression of the E7 oncoprotein by the IRBP promoter results in inactivation of $\mathrm{pRb}$ in developing photoreceptors, yet retinal tumors are observed only in mice also lacking p53 $(77,78)$. Animals expressing wild-type p53 display photoreceptor apoptosis during terminal differentiation, resulting in decreased differentiation and degeneration of the developing retina. While IRBP-E7 p53-null mice also display some photoreceptor apoptosis, this apoptosis is $\mathrm{p} 53$ independent, with proliferative foci emerging from the degenerating retina (77).

The critical role of p53 loss has been further supported by mouse models of genetic Rb1 deficiency. Similar to p53 wild-type IRBP-E7 mice, mice genetically lacking $R b 1$ displayed decreased retinal differentiation and increased retinal apoptosis $(79,80)$. It is not clear to what extent these ocular phenotypes might be attributable to an extra-embryonic function of $\mathrm{pRb}$, as was demonstrated for other neurologic and hematopoietic phenotypes observed in these embryos (81). Nevertheless, embryos genetically lacking $R b 1$ displayed apoptosis of multiple retinal cell types, including ganglion cells, bipolar cells, and photoreceptors. In contrast to this primarily apoptotic phenotype, chimeric mice lacking both $\mathrm{pRb}$ and $\mathrm{p} 107$ display retinal tumors that express markers of amacrine cell differentiation, in addition to accelerated retinal degeneration (82). In these mice, photoreceptors committed to differentiation undergo apoptosis, while early retinal precursors form proliferative foci, resulting in a mixed phenotype of aberrant apoptosis and aberrant proliferation. In these $\mathrm{pRb} /$ p107-deficient chimeric mice, loss of p53 dramatically accelerates tumor formation. These results suggest both that p107 is able to compensate for loss of $\mathrm{pRb}$ in mice and that loss of p53 accelerates tumor formation but is not absolutely required for retinal tumor development.

It is possible that in this model, mice genetically wild-type for $\mathrm{p} 53$ undergo functional inactivation of the p53 pathway in the process of developing retinal tumors. In fact, genetic mutations in P53 have never been observed in RBs isolated from human patients. Rather, human tumor samples display mutations in regulators of p53 (83), suggesting functional, rather than genetic, loss of this surveillance pathway. Additionally, nuclear exclusion of p53, resulting in abnormal cytoplasmic staining, has been reported in more invasive portions of RB tumors and in RB cell lines (84). The molecular function of p53 in suppressing retinal tumor development is also still unclear. Inhibition of apoptosis is not observed in the developing retinas of $\mathrm{pRb} / \mathrm{p} 107$ chimeric mice lacking p53, suggesting that the mechanism underlying accelerated tumor formation is not loss of p53-mediated apoptosis (82). In this system, loss of p53 may accelerate tumor formation through enhanced mutagen- 


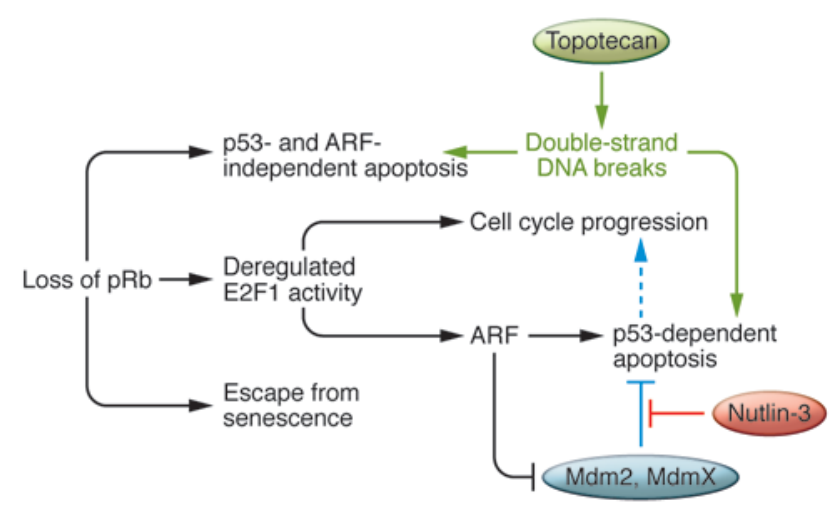

Figure 6

The role of p53-mediated apoptosis following $p R b$ loss. Loss of $p R b$ through genetic mutation results in activation of E2F transcription factors. Deregulated E2Fs can promote cell proliferation through transcription of cell cycle and DNA synthesis genes, but can also induce apoptosis through upregulation of ARF and p53 activity. This control mechanism is lost in the absence of p53. While loss of p53 is rare in RB tumors, amplification of the p53 inhibitors Mdm2 or MdmX (blue) can result in decreased p53 activity, thus inhibiting apoptosis and promoting cell proliferation. Inhibitors of Mdm2 and MdmX, such as nutlin-3 (red), can restore p53 activity to RB tumor cells by preventing association of $\mathrm{Mdm} 2$ and $\mathrm{MdmX}$ with p53, thus promoting p53-mediated apoptosis. Topotecan (green), another targeted therapy, functions by inhibiting topoisomerase I and creating DNA double-strand breaks, which triggers apoptosis through both p53-dependent and p53-independent pathways (128). Through alternative pathways, deregulated E2F activity resulting from $p R b$ loss can also result in p53-independent apoptosis, as well as escape from senescence and de-differentiation.

esis due to a defective DNA damage response (DDR). This possibility is consistent with the findings that $\mathrm{p} 53$ plays a critical role in genomic stability, protecting against chromosomal and DNA strand breakage following ionizing radiation and genotoxic stress, and that mice lacking p53 are prone to tumorigenesis (85-87) and have multiple developmental abnormalities, including retinal dysplasia $(88,89)$.

Interestingly, deregulated E2F1, which can result from loss of $\mathrm{pRb}$, can trigger apoptosis through a p53-dependent mechanism that results from the accumulation of DNA double-strand breaks (Figure 6 and refs. 90, 91). In response to DNA breaks, p53 activates the DDR, inducing cell cycle arrest mediated by $\mathrm{p} 21$ and $\mathrm{pRb}$ to allow for repair of the damaged genetic material, or triggering apoptosis if the lesions are not repairable (92). Therefore, in the absence of p53, E2F1-associated DNA damage may not be repaired, increasing mutagenesis and accelerating transformation. However, it is unknown whether activating DDR is actually an important biological barrier to $\mathrm{pRb}$-associated tumorigenesis. Accumulation of E2F1-mediated DNA damage occurs in pRbnull cells, but not in cells in which pRb is functionally inactivated by constitutive phosphorylation $(90,93)$. This suggests that a checkpoint mechanism may be triggered in response to completely deregulated E2F1, creating strong selective pressure to inactivate p53 (90). In a parallel pathway independent of DNA damage, E2F transcription factors also increase expression of the tumor suppressor ARF, which inhibits Mdm2, an E3 ubiquitin ligase that targets p53 for proteasomal degradation, collectively resulting in p53 activation (Figure 6 and ref. 94).

\section{Associated chromosomal alterations in RB}

$\mathrm{RB}$ is associated with a discrete set of chromosomal alterations that are frequently seen in combination with mutations of the $R B 1$ locus. These alterations include $+1 q,+6 p$, and $-16 q$, and these chromosomal regions may harbor genes that are critical for $\mathrm{RB}$ pathogenesis (95). MdmX, a protein related to $\mathrm{Mdm} 2$ that also functions to inhibit p53 (Figure 6), is located in a region of amplification at $1 \mathrm{q} 32$, making it a promising candidate as a contributor to RB development. $M D M X$ and $M D M 2$ are both candidate oncogenes for RB development, as the gain or amplification of these genes has been reported in $65 \%$ and $10 \%$ of $\mathrm{RB}$ cases, respectively (83). Amplification of these genes would be expected to functionally inactivate the p53 pathway and may explain the lack of genetic alterations observed at the p53 locus in human RB. However, some reports have demonstrated a lack of correlation between genomic amplification of MdmX and levels of its expressed mRNA (96). Nevertheless, amplification of MdmX has been shown to suppress p53-mediated cell death in retinoblasts lacking $R B 1$ and to promote their clonal cell proliferation (83). KIF14, a putative oncogene and regulator of mitosis, is another candidate gene located in the amplified region of chromosome $1(97,98)$. The expression of KIF14 is higher than that of $M D M X$ in retinoma and $\mathrm{RB}$ samples, and expression of this gene is more frequently elevated (99). Nevertheless, complete understanding of the contribution of either of these proteins to disease development and progression requires further study.

Additional candidate genes identified by chromosomal analysis include those encoding the transcription factor E2F3 and the chromatin remodeling factor and histone chaperone protein DEK (98), both of which are located on the amplified region of chromosome 6p. DEK has been identified as a proto-oncogene in multiple malignancies and may be associated with apoptosis inhibition (100-102). Its overexpression is associated with de-differentiation and proliferation (103), in addition to repair of DNA double-strand breaks (104) and inhibition of cellular senescence $(101,105)$. Other genes proposed as candidates for the progression of RB include the adhesion factor cadherin-11, P130, and MYCN (95). The precise roles of these genes in rebinoblastoma pathogenesis remain unknown.

\section{New treatments based on molecular pathway analysis}

Improved understanding of the molecular pathways intersecting with $\mathrm{pRb}$ has led to the development of new therapies to better target $\mathrm{RB}$ and other tumors harboring $R B 1$ mutations. Nutlin-3 is a small molecule inhibitor of Mdm 2 that also binds $\mathrm{MdmX}$ and prevents the association of both of these proteins with p53 (ref. 83 and Figure 6). Treatment with nutlin-3 restores the $\mathrm{p} 53$ pathway in RB cells that lack both pRb and p53 activity. The ability of nutlin-3 to inhibit the MdmX-p53 interaction is independent of its inhibition of Mdm2-p53 (83). When used in combination with the p53 inducer topotecan (Figure 6), nutlin3 functions synergistically to kill RB cells in vitro and results in an 82-fold reduction in tumor burden following subconjunctival injection in mouse models $(83,106)$. The combination of nutlin3 and topotecan does not produce any noted side effects in animal models, in contrast to systemic chemotherapeutic regimens. Nutlin-3 is currently in phase I clinical trials for the treatment of $\mathrm{RB}$, with results eagerly anticipated.

Another class of targeted therapies currently in phase I clinical trials for RB are the HDAC inhibitors (HDACi). Cells with elevated E2F1 activity have been found to be uniquely sensitive to HDACi 
through overexpression of proapoptotic factors (107). Cells lacking $\mathrm{pRb}$ have increased E2F1 activity, and RB-derived cell lines have demonstrated particular sensitivity to HDACi-induced apoptosis (108). In preclinical trials, HDACi inhibited growth of RB-derived tumors in both transgenic and xenograft murine models of RB, with minimal off-target effects (108), suggesting that HDACi may specifically inhibit the proliferation of RB tumor cells and thus have lower systemic toxicities relative to currently used chemotherapeutic agents.

An additional approach would be to target the initial precursor cell from which the tumor derives. The cell of origin of RB, however, remains quite controversial. There is some evidence that RB tumors express markers specific to cone precursor cells, including RXR $\gamma$ and TR $\beta 2$, and the long and medium wavelength (L/M) opsins (109). Furthermore, it has been reported that both cone precursors and $\mathrm{RB}$ cells express high levels of Mdm2 and $\mathrm{N}-\mathrm{Myc}$, which are required for their proliferation, and that the cone-specific RXR $\gamma$ induces $\mathrm{Mdm} 2$ expression in RB cells in vitro (109), which fits well with data describing loss of the p53 pathway in RB pathogenesis, as discussed above. However, while MDM2 expression has been observed in RB tumor samples, overexpression of this gene relative to normal retina has not been frequently observed (110). Alternatively, some data suggest that the p53 pathway may be inhibited in RB precursors through overexpression of activating E2F transcription factors, which decrease p53 activity by promoting p53 deacetylation (111). Therefore, while $\mathrm{RB}$ tumor cells have some resemblance to cone cells, definitive evidence that cone-specific genes contribute to tumor development is still lacking. The presence of a cone precursor to RB tumors might suggest that these tumors would be more concentrated in the fovea, the portion of the retina with highest cone density; however, this finding is not observed clinically. Other groups have suggested that RB might arise from an amacrine cell precursor, as these cells are the only cells observed to resist death when lacking both $R b 1$ and $p 107$ in mouse models of disease (112). Definitive determination of the cell of origin of RB could promote the development of therapies that specifically target RB cells, while sparing normal retinal tissue, and would shed light on the outstanding question of why retinal cells are so highly dependent on $\mathrm{pRb}$ to suppress tumor development.

\section{Localized delivery of non-targeted agents for RB treatment}

Despite the identification of multiple potential molecular targets for RB treatment, nutlin-3 remains one of the only targeted agents currently under clinical investigation for this disease. Significant efforts have been employed to investigate the localized delivery of broad-based chemotherapeutics into the ophthalmic artery to minimize toxicities associated with systemic RB treatment. Although reports of this approach have been described for more than 20 years, the currently used technique of intra-arterial injection of melphalan, a DNA-alkylating agent, was first performed in Japan seven years ago (113). While in vitro clonogenic studies showed that melphalan, among 12 chemotherapeutic agents, had the strongest cytotoxic effect on RB cells (114), to date there are no published in vivo data describing the long-term efficacy or toxicities of intraarterial melphalan in animal models of RB. Through phase III clinical trials in Japan and the United States, intra-arterial melphalan injection has been performed for RB more than 1,400 times (115). Reports have described a tumor response rate between $75 \%$ and $90 \%$ and a significant decrease in enucleation rates (116-118). Although there are minimal data regarding long-term follow-up of these patients at present, two-year event-free survival rates have been reported as roughly $70 \%$ (118). The lack of long-term survival and toxicity data, from both clinical trials and preclinical animal models, makes the long-term utility of this approach unclear. Complications observed in clinical trials have been serious and have included vitreous hemorrhage, microemboli to the retina and choroid, myositis, eyelid edema, orbital congestion with resulting dysmotility, choroidal atrophy, ophthalmic artery stenosis, and branch retinal artery occlusion, resulting in blindness $(119,120)$. Although the long-term rate of tumor recurrence or progression to bilateral disease is currently unknown, other treatments delivered by this approach are also under investigation $(121,122)$.

\section{Genetic testing to inform targeted therapies}

Widespread adoption of $R B 1$ genetic analysis would have a significant impact on treatment decisions and outcomes, without the risks associated with non-targeted approaches. Genetic testing for RB1 mutations has been limited by the time and costs required for whole gene analysis. The gene lacks known mutation hot spots; therefore, all exons and surrounding sequences must be analyzed individually. However, recently developed highthroughput approaches to gene analysis may allow clinicians and researchers to overcome this obstacle. Whole gene sequencing can directly inform patient care: if an individual who initially presents with unilateral disease is known to harbor a germline mutation, this would argue against enucleation as a primary treatment, because bilateral disease will almost inevitably develop in the future, so systemic chemotherapy would be favored. In contrast, patients who present with unilateral disease and no underlying germline mutation do not have the risk for RB development in the second eye. These infants can therefore be spared the toxicity of chemotherapy or radiation therapy by undergoing enucleation of the involved eye.

\section{Conclusions}

Since the discovery of $R B 1$, there have been profound advances in our understanding of the genetic and molecular dysfunctions underlying the development of $\mathrm{RB}$. Although the role of $\mathrm{pRb}$ in inducing cell cycle arrest and its involvement in regulating cell proliferation, genome integrity, and apoptosis have been extensively studied, the research has led to surprisingly few new targeted therapies for this disease. Similarly, identification of additional discrete genetic lesions associated with loss of RB1 has not been translated into targeted treatment approaches. We propose that with the development of high-throughput sequencing methods, widespread genetic analysis of $R B 1$ mutations may provide valuable information regarding disease severity, molecular pathophysiology, and treatment responses for patients with RB. Through this combination of molecular and genetic approaches, the development of more targeted, less toxic approaches to treatment should be achievable for this devastating childhood disease.

\section{Acknowledgments}

This work was supported by the National Ophthalmic Disease Genotyping Network (EyeGENE) NIH/NEI HHS-N-260-220700001-C (to J.M. O'Brien), NEI EY13812 (to J.M. O'Brien), EY02162 (to J.M. O'Brien), the Wayne and Gladys Valley Foundation (to J.M. O’Brien), That Man May See Foundation Inc. (to J.M. O’Brien), 
Research to Prevent Blindness (to J.M. O'Brien), and the Jeffrey W. Berger Foundation (to U.M. Sachdeva). This work is supported in part by an unrestricted grant from Research to Prevent Blindness Inc., New York, New York, USA.

1. Broaddus E, Topham A, Singh AD. Survival with retinoblastoma in the USA:1975-2004. $\mathrm{BrJ} \mathrm{Oph}$ thalmol. 2009;93(1):24-27.

2. Canturk S, et al. Survival of retinoblastoma in less-developed countries impact of socioeconomic and health-related indicators. $\mathrm{Br} \mathrm{J} \mathrm{Ophthalmol}$. 2010;94(11):1432-1436.

3. Chantada GL, et al. Strategies to manage retinoblastoma in developing countries. Pediatr Blood Cancer. 2011;56(3):341-348.

4. Chan HS, Gallie BL, Munier FL, Beck Popovic M. Chemotherapy for retinoblastoma. Ophthalmol Clin North Am. 2005;18(1):55-63.

5. Macdonald MR, Harrison RV, Wake M, Bliss B, Macdonald RE. Ototoxicity of carboplatin: comparing animal and clinical models at the Hospital for Sick Children. J Otolaryngol. 1994;23(3):151-159.

6. Mulvihill A, et al. Ocular motility changes after subtenon carboplatin chemotherapy for retinoblastoma. Arch Ophthalmol. 2003;121(8):1120-1124.

7. Kiratli H, Kocabeyoglu S, Bilgic S. Severe pseudopreseptal cellulitis following sub-Tenon's carboplatin injection for intraocular retinoblastoma. J Aapos. 2007;11(4):404-405.

8. Abramson DH, Frank CM, Dunkel IJ. A phase I/II study of subconjunctival carboplatin for intraocular retinoblastoma. Ophthalmology. 1999; 106(10):1947-1950.

9. Schmack I, Hubbard GB, Kang SJ, Aaberg TM Jr, Grossniklaus HE. Ischemic necrosis and atrophy of the optic nerve after periocular carboplatin injection for intraocular retinoblastoma. Am J Ophthalmol. 2006;142(2):310-315.

10. Pui CH, Relling MV. Topoisomerase II inhibitorrelated acute myeloid leukaemia. Br J Haematol. 2000;109(1):13-23.

11. Gombos DS, et al. Secondary acute myelogenous leukemia in patients with retinoblastoma: is chemotherapy a factor? Ophthalmology. 2007; 114(7):1378-1383.

12. Lin P, O'Brien JM. Frontiers in the management of retinoblastoma. Am J Ophthalmol. 2009 148(2):192-198.

13. Scott IU, et al. External beam radiotherapy in retinoblastoma: tumor control and comparison of 2 techniques. Arch Ophthalmol. 1999;117(6):766-770.

14. Wong FL, et al. Cancer incidence after retinoblastoma. Radiation dose and sarcoma risk. JAMA. 1997;278(15):1262-1267.

15. Bunin GR, Meadows AT, Emanuel BS, Buckley JD, Woods WG, Hammond GD. Pre- and postconception factors associated with sporadic heritable and nonheritable retinoblastoma. Cancer Res. 1989;49(20):5730-5735.

16. HarbourJW. Molecular basis of low-penetrance retinoblastoma. Arch Ophthalmol. 2001;119(11):1699-1704.

17. Moll AC, et al. Second primary tumors in patients with hereditary retinoblastoma: a register-based follow-up study, 1945-1994. Int J Cancer. 1996;67(4):515-519.

18. Eng C, et al. Mortality from second tumors among long-term survivors of retinoblastoma. J Natl Cancer Inst. 1993;85(14):1121-1128.

19. Fletcher O, Easton D, Anderson K, Gilham C, Jay M, Peto J. Lifetime risks of common cancers among retinoblastoma survivors. J Natl Cancer Inst. 2004;96(5):357-363.

20. Burkhart DL, Sage J. Cellular mechanisms of tumour suppression by the retinoblastoma gene. Nat Rev Cancer. 2008;8(9):671-682.

21. De Falco G, Comes F, Simone C. pRb: master of differentiation. Coupling irreversible cell cycle withdrawal with induction of muscle-specific tran-
Address correspondence to: Joan M. O’Brien, Scheie Eye Institute, University of Pennsylvania, 51 N. 39th St., Philadelphia, Pennsylvania 19104, USA. Phone: 215.662.8657; Fax: 215.662.9676; E-mail: joan.obrien@uphs.upenn.edu. scription. Oncogene. 2006;25(38):5244-5249.

22. Ferguson KL, et al. A cell-autonomous requirement for the cell cycle regulatory protein, $\mathrm{Rb}$, in neuronal migration. EMBO J. 2005;24(24):4381-4391.

23. Ferguson KL, Slack RS. The Rb pathway in neurogenesis. Neuroreport. 2001;12(9):A55-62.

24. Harbour JW. Overview of RB gene mutations in patients with retinoblastoma. Implications for clinical genetic screening. Ophthalmology. 1998; 105(8):1442-1447.

25. Xiao B, et al. Crystal structure of the retinoblastoma tumor suppressor protein bound to E2F and the molecular basis of its regulation. Proc Natl Acad Sci U S A. 2003;100(5):2363-2368.

26. Ji P, et al. An Rb-Skp2-p27 pathway mediates acute cell cycle inhibition by $\mathrm{Rb}$ and is retained in a partialpenetrance Rb mutant. Mol Cell. 2004;16(1):47-58.

27. Donovan SL, Schweers B, Martins R, Johnson D, Dyer MA. Compensation by tumor suppressor genes during retinal development in mice and humans. BMC Biol. 2006;4:14.

28. Grana X, Garriga J, Mayol X. Role of the retinoblastoma protein family, pRB, p107 and p130 in the negative control of cell growth. Oncogene. 1998; 17(25):3365-3383.

29. Cobrinik D. Pocket proteins and cell cycle control. Oncogene. 2005;24(17):2796-2809.

30. Chen HZ, Tsai SY, Leone G. Emerging roles of E2Fs in cancer: an exit from cell cycle control. Nat Rev Cancer. 2009;9(11):785-797.

31. Lacy ER, et al. p27 binds cyclin-CDK complexes through a sequential mechanism involving binding-induced protein folding. Nat Struct Mol Biol. 2004;11(4):358-364.

32. Chu I, et al. p27 phosphorylation by Src regulates inhibition of cyclin E-Cdk2. Cell. 2007;128(2):281-294.

33. Chu IM, Hengst L, Slingerland JM. The Cdk inhibitor $\mathrm{p} 27$ in human cancer: prognostic potential and relevance to anticancer therapy. Nat Rev Cancer. 2008;8(4):253-267.

34. Suzuki-Takahashi I, et al. The interactions of E2F with $\mathrm{pRB}$ and with $\mathrm{p} 107$ are regulated via the phosphorylation of $\mathrm{pRB}$ and $\mathrm{p} 107$ by a cyclin-dependent kinase. Oncogene. 1995;10(9):1691-1698.

35. Ianari A, et al. Proapoptotic function of the retinoblastoma tumor suppressor protein. Cancer Cell. 2009;15(3):184-194.

36. Fan G, Ma X, Kren BT, Steer CJ. The retinoblastoma gene product inhibits TGF-beta1 induced apoptosis in primary rat hepatocytes and human $\mathrm{HuH}-7$ hepatoma cells. Oncogene. 1996;12(9):1909-1919.

37. Gottlieb E, Oren M. p53 facilitates pRb cleavage in IL-3-deprived cells: novel pro-apoptotic activity of p53. EMBOJ. 1998;17(13):3587-3596.

38. Abouzeid H, Munier FL, Thonney F, Schorderet DF. Ten novel RB1 gene mutations in patients with retinoblastoma. Mol Vis. 2007;13:1740-1745.

39. Brehm A, Miska EA, McCance DJ, Reid JL, Bannister AJ, Kouzarides T. Retinoblastoma protein recruits histone deacetylase to repress transcription. Nature. 1998;391(6667):597-601.

40. Magnaghi-Jaulin L, et al. Retinoblastoma protein represses transcription by recruiting a histone deacetylase. Nature. 1998;391(6667):601-605

41. Binne UK, et al. Retinoblastoma protein and anaphase-promoting complex physically interact and functionally cooperate during cell-cycle exit. Nat Cell Biol. 2007;9(2):225-232.

42. Liu X, Marmorstein R. Structure of the retinoblastoma protein bound to adenovirus E1A reveals the molecular basis for viral oncoprotein inactivation of a tumor suppressor. Genes Dev. 2007;21(21):2711-2716.
43. Liu X, Marmorstein R. When viral oncoprotein meets tumor suppressor: a structural view. Genes Dev. 2006;20(17):2332-2337.

44. Yaginuma $Y$, et al. Analysis of the Rb gene and cyclindependent kinase 4 inhibitor genes (p16INK4 and p15INK4B) in human ovarian carcinoma cell lines. Exp Cell Res. 1997;233(2):233-239.

45. Henley SA, Francis SM, Demone J, Ainsworth P, Dick FA. A cancer derived mutation in the retinoblastoma gene with a distinct defect for LXCXE dependent interactions. Cancer Cell Int. 2010;10:8.

46. Isaac CE, et al. The retinoblastoma protein regulates pericentric heterochromatin. Mol Cell Biol. 2006;26(9):3659-3671.

47. Bourgo RJ, et al. RB restricts DNA damage-initiated tumorigenesis through an LXCXE-dependent mechanism of transcriptional control. Mol Cell. 2011;43(4):663-672.

48. Knudsen KE, et al. RB-dependent S-phase response to DNA damage. Mol Cell Biol. 2000;20(20):7751-7763.

49. Bosco EE, et al. The retinoblastoma tumor suppressor modifies the therapeutic response of breast cancer. J Clin Invest. 2007;117(1):218-228.

50. Derenzini $\mathrm{M}$, et al. Loss of retinoblastoma tumor suppressor protein makes human breast cancer cells more sensitive to antimetabolite exposure. Clin Cancer Res. 2008;14(7):2199-2209.

51. DiCiommo D, Gallie BL, Bremner R. Retinoblastoma: the disease, gene and protein provide critical leads to understand cancer. Semin Cancer Biol. 2000;10(4):255-269.

52. Retinoblastoma Genetics. Retinoblastoma Genetics web site. http://rb1-lsdb.d-lohmann.de. Updated January 31, 2006. Accessed December 15, 2011.

53. Dick FA. Structure-function analysis of the retinoblastoma tumor suppressor protein - is the whole a sum of its parts? Cell Div. 2007;2:26.

54. Sellers WR, et al. Stable binding to E2F is not required for the retinoblastoma protein to activate transcription, promote differentiation, and suppress tumor cell growth. Genes Dev. 1998;12(1):95-106.

55. Sidle A, et al. Activity of the retinoblastoma family proteins, pRB, p107, and p130, during cellular proliferation and differentiation. Crit Rev Biochem Mol Biol. 1996;31(3):237-271.

56. Chen PL, Scully P, Shew JY, Wang JY, Lee WH. Phosphorylation of the retinoblastoma gene product is modulated during the cell cycle and cellular differentiation. Cell. 1989;58(6):1193-1198.

57. Weinberg RA. The retinoblastoma protein and cell cycle control. Cell. 1995;81(3):323-330.

58. Tamrakar S, Rubin E, Ludlow JW. Role of $\mathrm{pRB}$ dephosphorylation in cell cycle regulation. Front Biosci. 2000;5:D121-D137.

59. DeCaprio JA, Furukawa Y, Ajchenbaum F, Griffin JD, Livingston DM. The retinoblastoma-susceptibility gene product becomes phosphorylated in multiple stages during cell cycle entry and progression. Proc Natl Acad Sci U S A. 1992;89(5):1795-1798.

60. Furukawa Y, et al. Expression and state of phosphorylation of the retinoblastoma susceptibility gene product in cycling and noncycling human hematopoietic cells. Proc Natl Acad Sci U S A. 1990; 87(7):2770-2774.

61. Dyson N. The regulation of E2F by pRB-family proteins. Genes Dev. 1998;12(15):2245-2262.

62. Yung Y, Walker JL, Roberts JM, Assoian RK. A Skp2 autoinduction loop and restriction point control. J Cell Biol. 2007;178(5):741-747.

63. Knudsen ES, WangJY. Differential regulation of retinoblastoma protein function by specific Cdk phosphorylation sites. J Biol Chem. 1996;271(14):8313-8320. 
64. Sherr CJ, Roberts JM. CDK inhibitors: positive and negative regulators of G1-phase progression. Genes Dev. 1999;13(12):1501-1512.

65 . Hernando $\mathrm{E}$, et al. Rb inactivation promotes genomic instability by uncoupling cell cycle progression from mitotic control. Nature. 2004;430(7001):797-802.

66. Manning AL, Longworth MS, Dyson NJ. Loss of pRB causes centromere dysfunction and chromosomal instability. Genes Dev. 2010;24(13):1364-1376.

67. Sotillo R, et al. Mad2 overexpression promotes aneuploidy and tumorigenesis in mice. Cancer Cell. 2007;11(1):9-23.

68. Gonzalo S, et al. Role of the RB1 family in stabilizing histone methylation at constitutive heterochromatin. Nat Cell Biol. 2005;7(4):420-428.

69. Longworth MS, Herr A, Ji JY, Dyson NJ. RBF1 promotes chromatin condensation through a conserved interaction with the Condensin II protein dCAP-D3. Genes Dev. 2008;22(8):1011-1024.

70. Squire J, Gallie BL, Phillips RA. A detailed analysis of chromosomal changes in heritable and non-heritable retinoblastoma. Hum Genet. 1985;70(4):291-301.

71. Windle JJ, et al. Retinoblastoma in transgenic mice. Nature. 1990;343(6259):665-669.

72. al-Ubaidi MR, et al. Bilateral retinal and brain tumors in transgenic mice expressing simian virus 40 large $\mathrm{T}$ antigen under control of the human interphotoreceptor retinoid-binding protein promoter. J Cell Biol. 1992;119(6):1681-1687.

73. Marcus DM, et al. Trilateral tumors in four different lines of transgenic mice expressing SV40 T-antigen. Invest Ophthalmol Vis Sci. 1996;37(2):392-396.

74. al-Ubaidi MR, Hollyfield JG, Overbeek PA, Baehr W. Photoreceptor degeneration induced by the expression of simian virus 40 large tumor antigen in the retina of transgenic mice. Proc Natl Acad Sci US A. 1992;89(4):1194-1198.

75. Mahon KA, Chepelinsky AB, Khillan JS, Overbeek PA, Piatigorsky J, Westphal H. Oncogenesis of the lens in transgenic mice. Science. 1987; 235(4796):1622-1628.

76. Conway RM, Wheeler SM, Murray TG, Jockovich ME, O’Brien JM. Retinoblastoma: animal models. Ophthalmol Clin North Am. 2005;18(1):25-39.

77. Howes KA, Ransom N, Papermaster DS, Lasudry JG, Albert DM, Windle JJ. Apoptosis or retinoblastoma: alternative fates of photoreceptors expressing the HPV-16 E7 gene in the presence or absence of p53. Genes Dev. 1994;8(11):1300-1310.

78. Mills MD, Windle JJ, Albert DM. Retinoblastoma in transgenic mice: models of hereditary retinoblastoma. Surv Ophthalmol. 1999;43(6):508-518.

79. Jacks T, Fazeli A, Schmitt EM, Bronson RT, Goodell MA, Weinberg RA. Effects of an Rb mutation in the mouse. Nature. 1992;359(6393):295-300

80. Lee EY, et al. Mice deficient for Rb are nonviable and show defects in neurogenesis and haematopoiesis. Nature. 1992;359(6393):288-294.

81. Wu L, et al. Extra-embryonic function of Rb is essential for embryonic development and viability. Nature. 2003;421(6926):942-947.

82. Robanus-Maandag E, et al. p107 is a suppressor of retinoblastoma development in pRb-deficient mice. Genes Dev. 1998;12(11):1599-1609.

83. Laurie NA, et al. Inactivation of the $\mathrm{p} 53$ pathway in retinoblastoma. Nature. 2006;444(7115):61-66.

84. Schlamp CL, Poulsen GL, Nork TM, Nickells RW. Nuclear exclusion of wild-type p53 in immortal ized human retinoblastoma cells. J Natl Cancer Inst. 1997;89(20):1530-1536.

85. Donehower LA, et al. Mice deficient for p53 are developmentally normal but susceptible to spontaneous tumours. Nature. 1992;356(6366):215-221.

86. Harvey M, McArthur MJ, Montgomery CA Jr, Butel JS, Bradley A, Donehower LA. Spontaneous and carcinogen-induced tumorigenesis in p53-deficient mice. Nat Genet. 1993;5(3):225-229.

87. Kemp CJ, Wheldon T, Balmain A. p53-deficient mice are extremely susceptible to radiation-induced tumorigenesis. Nat Genet. 1994;8(1):66-69.

88. Sah VP, Attardi LD, Mulligan GJ, Williams BO, Bronson RT, Jacks T. A subset of p53-deficient embryos exhibit exencephaly. Nat Genet. 1995;10(2):175-180.

89. Ikeda S, Hawes NL, Chang B, Avery CS, Smith RS, Nishina PM. Severe ocular abnormalities in C57BL/ 6 but not in 129/Sv p53-deficient mice. Invest Ophthalmol Vis Sci. 1999;40(8):1874-1878.

90. Pickering MT, Kowalik TF. Rb inactivation leads to E2F1-mediated DNA double-strand break accumulation. Oncogene. 2006;25(5):746-755.

91. Frame FM, Rogoff HA, Pickering MT, Cress WD, Kowalik TF. E2F1 induces MRN foci formation and a cell cycle checkpoint response in human fibroblasts. Oncogene. 2006;25(23):3258-3266.

92. Garner E, Raj K. Protective mechanisms of p53p21-pRb proteins against DNA damage-induced cell death. Cell Cycle. 2008;7(3):277-282.

93. Tort F, Bartkova J, Sehested M, Orntoft T, Lukas J, Bartek J. Retinoblastoma pathway defects show differential ability to activate the constitutive DNA damage response in human tumorigenesis. Cancer Res. 2006;66(21):10258-10263.

94. Sherr CJ, Weber JD. The ARF/p53 pathway. Curr Opin Genet Dev. 2000;10(1):94-99.

95. Corson TW, Gallie BL. One hit, two hits, three hits, more? Genomic changes in the development of retinoblastoma. Genes Chromosomes Cancer. 2007; 46(7):617-634

96. Gratias S, et al. Genomic gains on chromosome 1q in retinoblastoma: consequences on gene expression and association with clinical manifestation. Int J Cancer. 2005;116(4):555-563.

97. Corson TW, Huang A, Tsao MS, Gallie BL. KIF14 is a candidate oncogene in the $1 \mathrm{q}$ minimal region of genomic gain in multiple cancers. Oncogene. 2005;24(30):4741-4753

98. Dimaras H, et al. Loss of RB1 induces non-proliferative retinoma: increasing genomic instability correlates with progression to retinoblastoma. Hum Mol Genet. 2008;17(10):1363-1372

99. Bowles E, et al Profiling genomic copy number changes in retinoblastoma beyond loss of RB1. Genes Chromosomes Cancer. 2007;46(2):118-129.

100. Wise-Draper TM, Allen HV, Jones EE, Habash KB Matsuo H, Wells SI. Apoptosis inhibition by the human DEK oncoprotein involves interference with p53 functions. Mol Cell Biol. 2006;26(20):7506-7519.

101. Khodadoust MS, et al. Melanoma proliferation and chemoresistance controlled by the DEK oncogene. Cancer Res. 2009;69(16):6405-6413.

102. Secchiero P, Voltan R, di Iasio MG, Melloni E, Tiribelli M, Zauli G. The oncogene DEK promotes leukemic cell survival and is downregulated by both Nutlin-3 and chlorambucil in B-chronic lymphocytic leukemic cells. Clin Cancer Res. 2010;16(6):1824-1833.

103. Wise-Draper TM, et al. DEK proto-oncogene expression interferes with the normal epithelial differentiation program. Am J Pathol. 2009;174(1):71-81.

104.Kappes F, et al. DEK is a poly(ADP-ribose) acceptor in apoptosis and mediates resistance to genotoxic stress. Mol Cell Biol. 2008;28(10):3245-3257.

105. Wise-Draper TM, et al. The human DEK protooncogene is a senescence inhibitor and an upregulated target of high-risk human papillomavirus E7. J Virol. 2005;79(22):14309-14317.

106.Brennan RC, et al. Targeting the $\mathrm{p} 53$ pathway in retinoblastoma with subconjunctival Nutlin-3a. Cancer Res. 2011;71(12):4205-4213.

107. Zhao Y, Tan J, Zhuang L, Jiang X, Liu ET, Yu Q. Inhibitors of histone deacetylases target the RbE2F1 pathway for apoptosis induction through activation of proapoptotic protein Bim. Proc Natl Acad Sci U S A. 2005;102(44):16090-16095

108. Dalgard CL, Van Quill KR, O'Brien JM. Evaluation of the in vitro and in vivo antitumor activity of histone deacetylase inhibitors for the therapy of retinoblas- toma. Clin Cancer Res. 2008;14(10):3113-3123.

109. Xu XL, et al. Retinoblastoma has properties of a cone precursor tumor and depends upon cone-specific MDM2 signaling. Cell. 2009;137(6):1018-1031.

110. Guo Y, Pajovic S, Gallie BL. Expression of p14ARF, MDM2, and MDM4 in human retinoblastoma. Biochem Biophys Res Commun. 2008;375(1):1-5.

111. Chen D, Pacal M, Wenzel P, Knoepfler PS, Leone G, Bremner R. Division and apoptosis of E2f-deficient retinal progenitors. Nature. 2009;462(7275):925-929.

112. Chen D, Livne-bar I, Vanderluit JL, Slack RS, Agochiya M, Bremner R. Cell-specific effects of RB or $\mathrm{RB} / \mathrm{p} 107$ loss on retinal development implicate an intrinsically death-resistant cell-of-origin in retinoblastoma. Cancer Cell. 2004;5(6):539-551.

113. Yamane T, Kaneko A, Mohri M. The technique of ophthalmic arterial infusion therapy for patients with intraocular retinoblastoma. Int J Clin Oncol. 2004;9(2):69-73.

114.Inomata M, Kaneko A. Chemosensitivity profiles of primary and cultured human retinoblastoma cells in a human tumor clonogenic assay. Jpn J Cancer Res. 1987;78(8):858-868.

115. Graeber CP, et al. Histopathologic findings of eyes enucleated after treatment with chemosurgery for retinoblastoma. Open Ophthalmol J. 2011;5:1-5.

116. Shields CL, et al. Intra-arterial chemotherapy for retinoblastoma: report no. 1, control of retinal tumors, subretinal seeds, and vitreous seeds. Arch Ophthalmol. 2011;129(11):1399-1406.

117. Peterson EC, Elhammady MS, Quintero-Wolfe S, Murray TG, Aziz-Sultan MA. Selective ophthalmic artery infusion of chemotherapy for advanced intraocular retinoblastoma: initial experience with 17 tumors. J Neurosurg. 2011;114(6):1603-1608

118. Gobin YP, Dunkel IJ, Marr BP, Brodie SE, Abramson $\mathrm{DH}$. Intra-arterial chemotherapy for the management of retinoblastoma: four-year experience. Arch Ophthalmol. 2011;129(6):732-737.

119. Shields CL, et al. Intra-arterial chemotherapy for retinoblastoma: report no. 2, treatment complications. Arch Ophthalmol. 2011;129(11):1407-1415.

120.Vajzovic LM, et al. Supraselective intra-arterial chemotherapy: evaluation of treatment-related complications in advanced retinoblastoma. Clin Ophthalmol. 2011;5:171-176.

121.Antczak C, et al. Revisiting old drugs as novel agents for retinoblastoma: in vitro and in vivo antitumor activity of cardenolides. Invest Ophthalmol Vis Sci. 2009;50(7):3065-3073

122.Patel $\mathrm{M}$, et al. Intra-arterial and oral digoxin therapy for retinoblastoma. Ophthalmic Genet. 2011; 32(3):147-150

123.Eser U, Falleur-Fettig M, Johnson A, Skotheim JM. Commitment to a cellular transition precedes genome-wide transcriptional change. Mol Cell. 2011;43(4):515-527.

124.Saenz Robles MT, Case A, Chong JL, Leone G, Pipas JM. The retinoblastoma tumor suppressor regulates a xenobiotic detoxification pathway. PLoS ONE. 2010;6(10):e26019.

125.Sdek P, et al. Rb and p130 control cell cycle gene silencing to maintain the postmitotic phenotype in cardiac myocytes. J Cell Biol. 2011;194(3):407-423.

126. Harbour JW, Luo RX, Dei Santi A, Postigo AA, Dean DC. Cdk phosphorylation triggers sequential intramolecular interactions that progressively block Rb functions as cells move through G1. Cell. 1999;98(6):859-869.

127.Zarkowska T, Mittnacht S. Differential phosphorylation of the retinoblastoma protein by G1/S cyclin-dependent kinases. J Biol Chem. 1997; 272(19):12738-12746.

128. Tomicic MT, Christmann M, Kaina B. Topotecan triggers apoptosis in p53-deficient cells by forcing degradation of XIAP and survivin thereby activating caspase-3-mediated Bid cleavage. J Pharmacol Exp Ther. 2010;332(1):316-325. 